\title{
EDITORIAL AND COMMENT
}

\section{Medicaid Coverage for Weight Loss Counseling May Make 'Cents'}

\author{
Sara N. Bleich, PhD and Bradley J. Herring, PhD \\ Department of Health Policy and Management, Bloomberg School of Public Health, Johns Hopkins University, Baltimore, MD, USA.
}

$\mathrm{J}$ Gen Intern Med 28(1):3-5

DOI: $10.1007 / \mathrm{s} 11606-012-2201-7$

(c) Society of General Internal Medicine 2012

A dult obesity affects roughly one third of US adults ${ }^{1}$ and is estimated to cost $\$ 147$ billion annually, \$28 million of which is financed by Medicaid, ${ }^{2}$ the joint federal/ state public insurance program for low-income Americans. Because low-income people are more likely to be obese and because the 2010 Affordable Care Act (ACA) is expected to increase the number of people with Medicaid as their primary source of coverage from about 34 million to 43 million (not including people who are dually eligible for Medicaid and Medicare), ${ }^{3}$ Medicaid coverage of obesity treatments is a timely policy issue. Beginning in 2014, the Medicaid program will begin to cover millions more Americans with diagnostic obesity services, but the subsequent therapeutic care is currently limited.

The clinical treatment for obesity generally includes some combination of nutritional counseling, weight-loss medication and bariatric surgery. Since the Centers for Medicare and Medicaid (CMS) recognized obesity as a disease in 2004, most of the state activity related to Medicaid coverage for obesity care has focused on bariatric surgery. As of 2010, all state Medicaid programs provided some coverage for obesity care, but while 45 states cover bariatric surgery (with various eligibility restrictions), only 26 provide nutritional counseling and only 10 provide drug therapy. ${ }^{4}$ This discrepancy for bariatric surgery, which costs at least $\$ 10,000$ per person, versus less invasive and less expensive nutritional program and weight-loss drugs, which under federal law are one of the classes of drugs that Medicaid programs can exclude from coverage, is notable.

In this issue of JGIM, the article by Mitchell et al. ${ }^{5}$ suggests that coverage of weight-loss counseling programs may be a good investment for Medicaid. Weight Watchers, which was the focus of this article, runs approximately 20,000 meetings a week around the country and offers online food tracking tools that are designed to easily help people navigate the food environment. Mitchell et al. found that enrollees in Tennessee's TennCare Medicaid program who joined Weight Watchers typically lost about $1.9 \mathrm{~kg}$

Published online September 6, 2012
(4.2 lb) after seven sessions and that participants who attended more meetings lost more weight. The authors also conducted sensitivity analyses including enrollees who attended the initial session but subsequently withdrew from the program and made the conservative assumption that those individuals lost no weight. This still yielded a $1.1-\mathrm{kg}$ (2.4-lb) weight loss from the intervention. The cost to Medicaid was nominal: \$19 for an introductory session and $\$ 11$ for each follow-up session with Medicaid enrollees contributing \$1 per session.

These findings by Mitchell et al. are consistent with other research on behavioral weight-loss programs, which observed an average weight loss of 4 to $7 \mathrm{~kg}$ ( 8.8 to $15.4 \mathrm{lb}$ ) after 12 to 26 sessions. ${ }^{6}$ These programs are also associated with a decrease in the incidence of weight-related comorbidities such as type 2 diabetes $^{7}$ and have been shown to be as cost-effective as bariatric surgery and more cost-effective than drug therapy. ${ }^{8}$ A simple "back of the envelope" calculation using Mitchell et al.'s findings helps illustrate this intuition: TennCare's Weight Watchers program costs an average of $\$ 85$ ( $\$ 19$ for the initial session and \$11 for each subsequent session) for a (conservative) weight loss of $2.4 \mathrm{lb}$, yielding a net cost of $\$ 35$ per pound $(\$ 85 / 2.4 \mathrm{lb})$. Alternatively, a $243-1 b$ person (i.e., the median weight for an obese person in their TennCare sample) who receives bariatric surgery and loses the typical $60 \%$ of his/her weight would cost about $\$ 12,500$ for a weight loss of $146 \mathrm{lb}$, yielding a higher net cost of $\$ 86$ per pound $(\$ 12,500 / 146 \mathrm{lb})$. This $\$ 12,500$ estimate is based on the Medicare fee schedule for an individual getting an OR procedure with a co-morbidity and converted to an estimated Medicaid payment using average Medicaid/ Medicare charge ratios. For private insurers looking to adopt this benefit, the cost per pound would be considerably higher as Medicaid pays about a third less than private insurers.

A primary goal of the $2010 \mathrm{ACA}$ is to expand access to health insurance coverage in 2014 , in part by increasing eligibility for Medicaid to all nonelderly people earning up to $133 \%$ of the federal poverty level (FPL), $\$ 25,390$ for a family of three. The June 2012 Supreme Court ruling allows states to opt out of the Medicaid expansion, which led the Congressional Budget Office to reduce its estimate of the number of Medicaid enrollees in 2015 from about 49 million to 43 million, where some of these 6 million people 
live in states that are likely to expand Medicaid to a threshold lower than $133 \%$ FPL and others live in states unlikely to expand Medicaid at all. ${ }^{3}$ Even with this estimated reduction in new enrollees, the size of the Medicaid program and the disproportionate impact of obesity among this group suggests that increased access to insurance coverage of behavioral weight-loss programs like Weight Watchers could be an important step towards reducing obesity at the population level.

Moreover, the health reform law is also expected to increase obesity screening and subsequent obesity treatment among those ultimately covered by Medicaid. The ACA incentivizes state Medicaid programs to cover the preventive services and immunizations recommended by the US Preventive Service Task Force (USPSTF) without patient cost sharing by increasing federal funding to states adopting these guidelines. (In contrast, Medicare and private insurers are simply required to cover the USPSTF recommendations.) These USPSTF guidelines were recently updated to now recommend that clinicians screen patients for obesity and then offer or refer those patients who meet or exceed that level "intensive, multi-component behavioral interventions" to help them lose weight. ${ }^{6}$ The federal government, which provides states with "matching funds" for Medicaid that currently averages $56 \%$ (and varies inversely with state income), will likely encourage states to cover these recommended preventive services with no patient cost sharing by increasing these federal matching funds, for all healthcare services, by one percentage point starting in 2013. However, it is conceivable that the recent Supreme Court decision will weaken this provision as well. In return for participating in the Medicaid expansion, some states may try to negotiate with CMS for more flexibility - such as fixed "block grant" funding to spend on Medicaid with fewer federal requirements on how it is spent. As a result, the ACA's incentives for covering USPSTF services may disappear for these states granted waivers.

Our assessment is that joint coverage for USPSTF screening and behavioral weight-loss programs in the Medicaid program may be critical for both obesity control and cost containment. Screening for obesity without also covering the cost of weight-loss counseling may have a minimal effect on obesity rates because a weekly fee of, say, $\$ 11$ paid entirely out-of-pocket may simply be unaffordable to most people at or near poverty. Likewise, covering the cost of weight-loss counseling without also initially screening for obesity may also have a muted effect on obesity rates - perhaps illustrated by Mitchell et al.'s observation that only 1,600 out of 480,000 likely eligible TennCare enrollees actually signed up for Weight Watchers. Other research suggests that an obesity diagnosis is the biggest predictor of whether patients receive weight-related counseling, and this knowledge increases the likelihood that patients will engage in weight-loss behaviors. Having said that, because sub-optimal obesity care from physicians results from a variety of barriers (e.g., lack of time, inadequate training) and negative attitudes (e.g., weight stigma, doubt that counseling works, feeling that obesity is the responsibility of the patient), providing coverage for effective commercial weight-loss programs may also help Medicaid enrollees lose weight where the health-care system cannot.

The increase in obesity-related medical expenditures over the past decade has been primarily driven by rising prevalence not by higher costs among obese people. ${ }^{2}$ Currently, only a third of obese patients receive an obesity diagnosis and a fifth receive weight-related counseling. ${ }^{9}$ Medicaid coverage of both USPSTF-recommended obesity screening and commercial weight-loss programs could potentially help to reduce the prevalence of obesity at the population level in a relatively cost-effective manner. Although the TennCare partnership was a pilot program that has since ended, Mitchell et al. note that the private managed care plans continue to offer coverage for Weight Watchers voluntarily. Other states such as West Virginia have offered Weight Watchers Medicaid enrollees for several years (beginning in 2007), and several others states (e.g., California, Colorado Connecticut, Georgia, Indiana, Kentucky, Maine, Missouri, Nevada, New Hampshire, New York, Ohio, Virginia and Wisconsin) are reportedly considering providing the benefit. ${ }^{10}$ The coverage of commercial weight-loss programs like Weight Watchers by the Medicaid program may not solve the problem of obesity, but - given the magnitude of the epidemic - even modest reductions in weight can lead to significant health benefits and reduced costs.

Corresponding Author: Sara N. Bleich, PhD; Department of Health Policy and Management, Bloomberg School of Public Health, Johns Hopkins University, 624 N. Broadway, Room 451, Baltimore, MD 21205, USA (e-mail: sbleich@jhsph.edu).

\section{REFERENCES}

1. Flegal KM, Carroll MD, Ogden $\mathbf{C L}$, et al. Prevalence and trends in obesity among US adults, 1999-2008. JAMA. 2010;303(3):235-41.

2. Finkelstein EA, Trogdon JG, Cohen JW, et al. Annual Medical Spending Attributable To Obesity: Payer- And Service-Specific Estimates. Health Aff (Millwood). 2009.

3. Congressional Budget Office. Estimates for the Insurance Coverage Provisions of the Affordable Care Act Updated for the Recent Supreme Court Decision: Congressional Budget Office July 2012.

4. Lee JS, Sheer JL, Lopez N, et al. Coverage of obesity treatment: a stateby-state analysis of Medicaid and state insurance laws. Public Health Rep. 2010;125(4):596-604.

5. Mitchell NS, Ellison MC, Hill Jo, et al. Evaluation of the effectiveness of making Weight Watchers available to Tennessee Medicaid 
(TennCare) recipients. J Gen Intern Med. 2012; doi:10.1007/s11606012-2083-8.

6. Moyer VA. Screening for and Management of Obesity in Adults: US Preventive Services Task Force Recommendation Statement. Ann Intern Med. 2012.

7. Knowler WC, Barrett-Connor E, Fowler SE, et al. Reduction in the incidence of type 2 diabetes with lifestyle intervention or metformin. N Engl J Med. 2002;346(6):393-403.
8. Roux L, Kuntz KM, Donaldson C, et al. Economic evaluation of weight loss interventions in overweight and obese women. Obesity (Silver Spring). 2006;14(6): 1093-106.

9. Bleich SN, Pickett-Blakely O, Cooper LA. Physician practice patterns of obesity diagnosis and weight-related counseling. Patient Educ Couns. 2011;82(1):123-9.

10. Breen T. W.Va. to Offer Free Weight Watchers Plan. Washington Post. January 27, 2007. 